\title{
LAMININ-332 IMMUNOHISTOCHEMICAL EXPRESSION IN EPITHELIAL ODONTOGENIC TUMOR (AMELOBLASTOMA) VERSUS ORAL NON-ODONTOGENIC EPITHELIAL TUMORS (SQUAMOUS CELL CARCINOMA) IN RELATION TO THEIR HISTOLOGICAL DIFFERENTIATION
}

\author{
Amr H. El Bolok* and Sherif F. Elgayar**
}

\begin{abstract}
Objecctive: This study was conducted to correlate the expression of Laminin-332 with different histological variants of Squamous cell carcinoma and ameloblastoma.

Study Design: The material for the study included 60 formalin-fixed paraffin-embedded tissue blocks of SCC (11 well-differentiated OSCC, 11 moderately differentiated OSCC and 8 poorly differentiated OSCC) and ameloblastoma (15 follicular form, 8 plexiform ameloblastoma, 4 peripheral ameloblastoma and 3 ameloblastic carcinoma) retrieved from the Department of Oral Pathology, Minia University. The lesions were immunostained Laminin-332 individually. Immunoreactivity for each marker was assessed by scoring scale and statistical analysis was performed.
\end{abstract}

Results: The results showed a significant increase in Laminin-332 expression in welldifferentiated SCC and conventional ameloblastoma when compared to poorly differentiated SCC and ameloblastic carcinoma respectively ( $\mathrm{P}$ value $<0.05)$.

Conclusion: Immunohistochemical expression of Laminin-332 is directly proportional to tumor cells differentiation either in ameloblastoma and OSCC.

KEY WORDS: Squamous cell carcinoma, Ameloblastoma, Laminin-332.

\section{INTRODUCTION}

The main role of laminin 332 (formerly termed laminin 5, kalinin, nicein, ladsin and epiligrin) in normal tissues is in the maintenance of epithelial- mesenchymal cohesion in tissues exposed to external disruptive forces, including the skin, stratified squamous mucosa, the amnion and the cornea $^{1}$.

*Assist Professor, Oral Pathology Department, Minia University

**Lecturer, Oral Pathology Department, Minia University 
Laminins act as major basement membrane zone (BMZ) ligands for epithelial and carcinoma cells, supporting spreading, attachment, migration and invasion $^{2}$. One of the unique functions of laminin 332 in epidermal cells is its ability to interact with two major epithelial integrin receptors, $\alpha 3 \beta 1$ and $\alpha 6 \beta 4^{3}$, and its ability to promote the formation of two separate types of attachment structures: 1 . stable anchoring contacts (SACs) and 2. focal adhesions ${ }^{4}$. SACs form hemidesmosomes which link the keratincontaining intermediate filament cytoskeleton to the BMZ. SACs provide stable adhesion to epidermal cells. Whereas focal adhesions provide short-term adhesion through reversible associations of integrins, SAC-derived stable adhesion in epidermal cells is derived from a more complex assembly of integrins and integrin-associated proteins, and provides an increased resistance to disruptive forces ${ }^{5}$

The expression of integrins, among other classes of adhesion molecules, is altered in metastatic and invasive cells. It has been reported that integrin expression is altered in different types of tumors including OSCC but interestingly both overexpression and loss of expression expression have been reported. In cultured cells, various expressions of integrins can inhibit or induce metastatic and invasive behavior of the cells ${ }^{6}$.

It has been hypothesized that epithelial and endothelial cells interact with the laminin component of basement membranes via a cell surface laminin receptor molecule. It has also been proposed that the expression of this molecule may be involved in the invasion of carcinoma cells from their tissue of origin and their subsequent penetration through blood vessel basement membranes. Numerous normal human epithelial and endothelial cell types, as well as pulmonary macrophages, are shown to express laminin receptor to varying degrees?

Aim of our study to evaluate the expression of Laminin-332 in various grades of oral squamous cell carcinoma and ameloblastoma, and to compare between the expressions of both tumors in their various histological grades.

\section{MATERIAL AND METHODS}

Thirty cases formalin-fixed, paraffin-embeded tissue blocks of SCC (11 well differentiated, 11 Moderately differentiated and 8 poorly differentiated), and thirty cases Of ameloblastoma (15 follicular form, 8 plexiform ameloblastoma, 4 peripheral ameloblastoma and 3 ameloblastic carcinoma) retrieved from the Department of Oral Pathology, Minia University, were included in the study. To confirm the diagnosis, $4 \mu \mathrm{m}$ thick sections were stained with haematoxylin and eosin (H\&E) and examined by light microscope.

OSCC and ameloblastoma were designated as group 1 and 2 respectively. Group1 was subdivided according to differentiation into subgroup 1.a. for well differentiated OSCC, 1.b. for moderately differentiated OSCC and 1.c. for poorly differentiated OSCC.

As well as ameloblastomas were subdivided according to their histological variants to: group 2.a. for follicular, 2.b.for plexiform, 2.c for peripheral ameloblastoma, and 2.d for ameloblastic carcinoma.

For immunohistochemical staining, paraffin blocks were cut at $4 \mu \mathrm{m}$ thick sections and were mounted on electrically charged glass slides. Sections were de-paraffinized with xylene and rehydrated in graded alcohol. Sections were immersed in citrate buffer and treated in a microwave before the staining procedures. For immunostaining, a universal kit UltraVision $^{\mathrm{TM}}$ Quanto Detection System HRP DAB cat\#TL-060-QHD (Thermo scientific) was used. Peroxidase-antiperoxidase method of immunstaining using the biotin-streptavidin system was carried out. $3 \%$ hydrogen peroxide was applied to the sections to block endogenous peroxidase activity. The sections were immunolabeled using the primary antibodies mouse monocolonal AntiLaminin-332 (laminin gamma2) which is a major component of the basement membrane of epithelium, and then incubated overnight at room temperature. After rinsing with phosphate buffered saline (PBS), sections were covered by the link antibody, followed 
by streptavidin labeling antibody. After rinsing with PBS, DAB chromogen was applied to the sections followed by the counterstain. Sections were dehydrated in graded alcohol, cleared in xylene and mounted.

Immuno-stained specimens evaluated on two separate occasion 48 hours apart by two different pathologists. Calibration was accepted if evaluation for each case was similar.

To evaluate the staining for slide the following semi-quantitative scale was used. Complete lack of immunoreaction take the score 0 , mild positive scored as one, moderate staining scoring as two and strong positive immune-staining scored as three.

Statistical analysis was performed using SPSS version 16.0 (SPSS Inc., Chicago, IL, USA). For statistical evaluation, the groups were evaluated using paired sample $\mathrm{t}$ test $\mathrm{p}$ value] 0.05 were considered statistical significant.

\section{Statistical analysis}

All the data were collected, tabulated and statistically analyzed using computer software named the Statistical Package for Social Science (SPSS version 16). Data in the present study were presented as mean and standard deviation (SD). The difference between the sub-groups was statistically analyzed using the $\mathrm{F}$ value of analysis of variance (ANOVA). The comparisons between each two groups were determined by using an independentsamples $t$ test. The level of significance was established at a value of $\mathrm{P}<0.05$.

\section{RESULTS}

Immunohistochemical staining of Laminnin-332 in oral squamous carcinoma showed strong positive immunohistochemical in well-differentiated SCC, some showed strong staining at the keratin pearls (Fig. 1.a). Moderate to poor immunohistochemical reaction in moderate $\mathrm{SCC}$, some cases showed

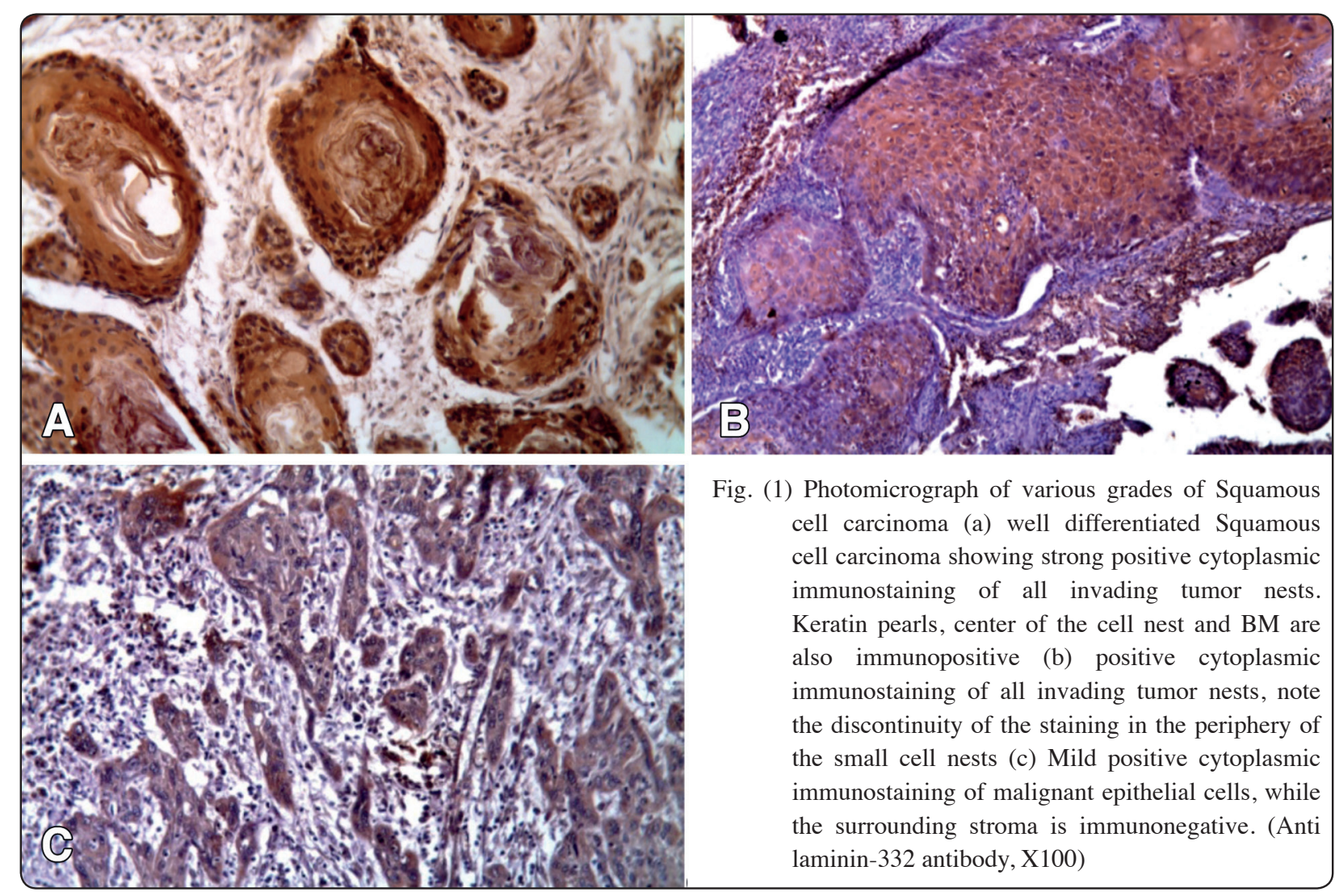




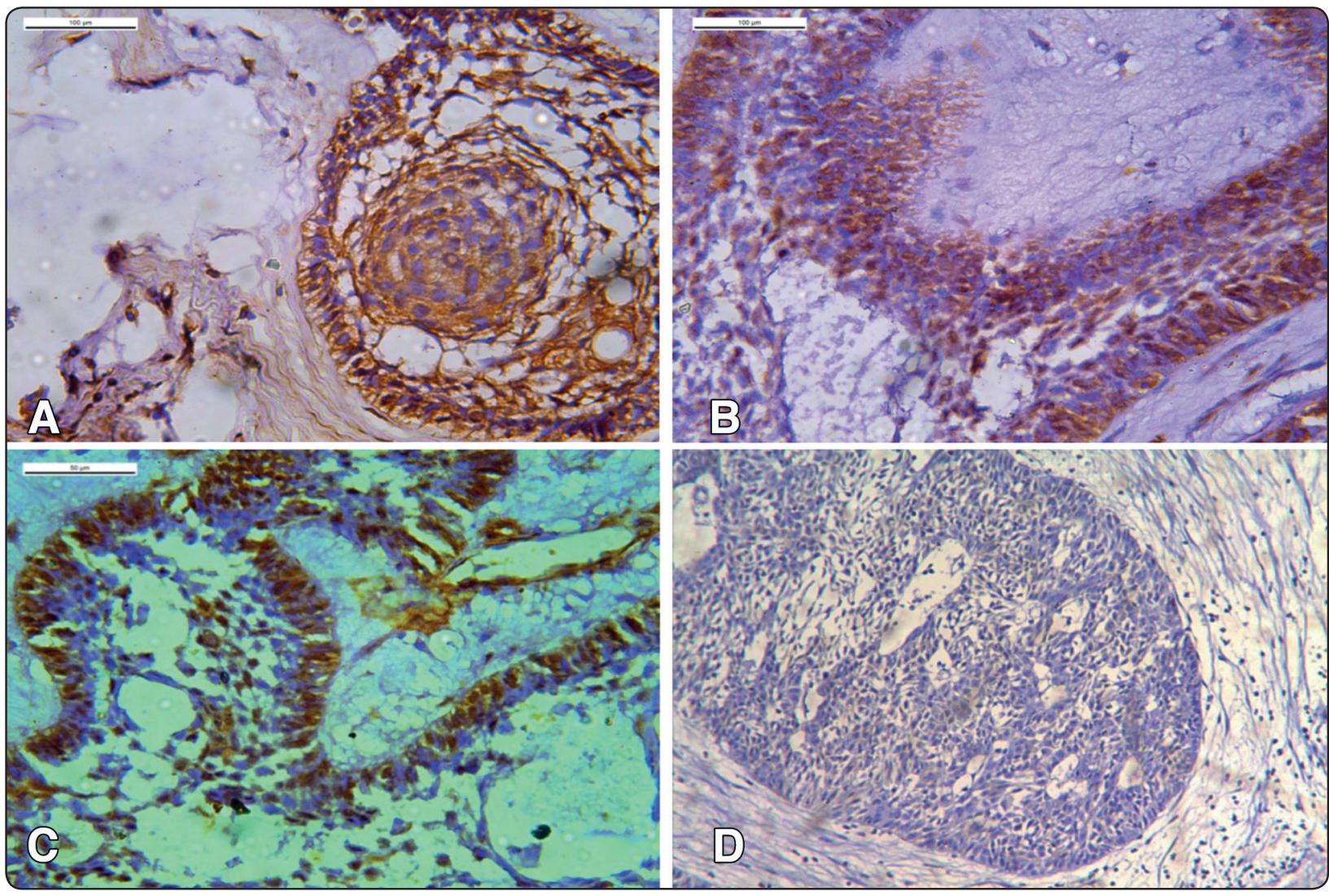

Fig. (2): Photomicrograph of various cases of ameloblastoma note the deep staining around the ameloblast like cells in follicular type and central stellate reticulum like cells with squamous metaplasia (a), plexiform (b) and peripheral (c) note the weak staining of regular stellate reticulum like cells, while it was negatively stained in ameloblastic carcinoma (d) (anti laminin-332 antibody x200)

discontinuous staining at the periphery of their cell nests (Fig.1.b.) and poor to negative staining in poorly differentiated SCC (Fig.1.c).

As well as Immunohistochemical staining of Laminnin-332 in histological variants of ameloblastoma showed strong positive immunohistochemical in the peripheral ameloblast like cells and weak to negative staining in stellate reticulum like cells of both follicular and plexiform pattern as well as in the peripheral form ameloblastoma (Fig. 2.a, b and c) and poor to negative staining ameloblastic carcinoma (Fig. 2.d)

\section{Statistical results}

For group 1 one way ANOVA test was statistically significant (table 1), while independent samples $t$ test between each 2 different subgroups showed statistically insignificance between groups 1.a and $1 . b$ while comparison between both groups $1 \mathrm{a}$ and $\mathrm{b}$ with 1c showed high significant value (table 2) TABLE (1) Mean values of Laminin-332, among the subgroup of squamous cell carcinoma:

\begin{tabular}{|c|c|c|c|c|}
\hline $\begin{array}{c}\text { Group I (squamous cell } \\
\text { carcinoma) }\end{array}$ & $\begin{array}{c}\text { 1a (well } \\
\text { Differentiated) }\end{array}$ & $\begin{array}{c}1 \mathrm{~b} \text { (Moderately } \\
\text { differentiated) }\end{array}$ & $\begin{array}{c}\text { 1c (Poorly } \\
\text { differentiated) }\end{array}$ & $\begin{array}{c}\text { ANOVA } \\
\text { P-values }\end{array}$ \\
\hline & $2.63 \pm 0.50$ & $2.54 \pm 0.50$ & $0.55 \pm 0.52$ & $\begin{array}{c}49.509 \\
\mathrm{P}<0.001^{*}\end{array}$ \\
\hline
\end{tabular}

*Significant value $(P<0.05)$ 
TABLE (2) Individual sample $t$ test among the subgroups of squamous cell carcinoma:

\begin{tabular}{|c|c|c|}
\hline 1a vs 1b & $\begin{array}{c}\text { t-test } \\
0.415\end{array}$ & $\begin{array}{c}\text { P-values } \\
0.682\end{array}$ \\
\hline \multirow{2}{*}{ 1a vs 1c } & t-test & P-values \\
& 8.995 & $\mathrm{P}=0.000^{*}$ \\
\hline \multirow{2}{*}{ 1b vs 1c } & t-test & $\mathrm{P}$-values \\
& 8.443 & $\mathrm{P}=0.000^{*}$ \\
\hline
\end{tabular}

*Significant value $(P<0.05)$

The mean values of the different subgroups of group 1 are shown in figure 3 .

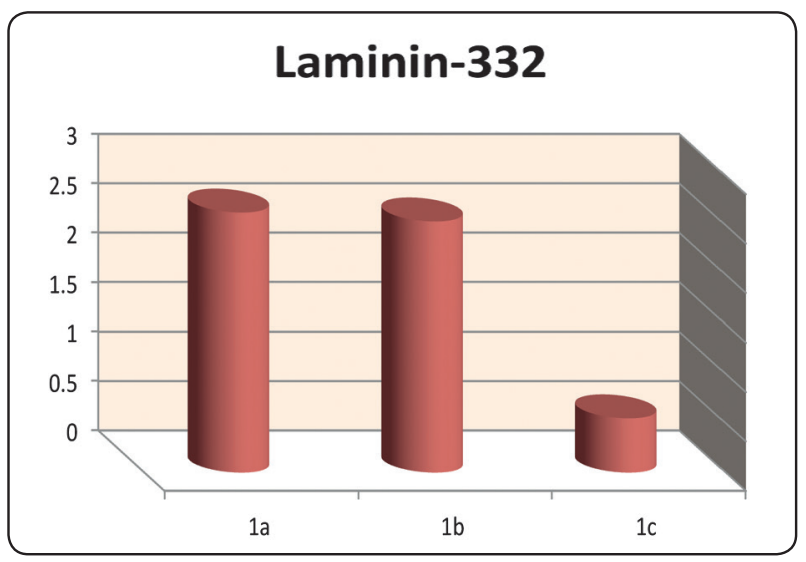

Fig. (3) Mean values of Laminin-332, among the subgroup of squamous cell carcinoma:

For group 2 one way ANOVA test was statistically significant (table 3 ), while independent samples $t$ test between each 2 different subgroups showed statistically insignificance between groups 2.a , 2.b and 2.c while comparison between groups 2a , 2.b and 2.c with 2.d showed high significant value ( table 4)
TABLE (4) Individual sample $t$ test among the subgroups of ameloblastoma variants:

\begin{tabular}{|c|c|c|}
\hline 2a vs 2b & t-test & P-values \\
& 0.191 & 0.850 \\
\hline \multirow{2}{*}{ 2a vs 2c } & t-test & P-values \\
& 0.587 & $\mathrm{P}=0.565$ \\
\hline \multirow{2}{*}{ 2a vs 2d } & t-test & P-values \\
& 7.379 & $\mathrm{P}=0.000^{*}$ \\
\hline \multirow{2}{*}{ 2b vs 2c } & t-test & $\mathrm{P}$-values \\
& 0.381 & $\mathrm{P}=0.711$ \\
\hline \multirow{2}{*}{ 2b vs 2d } & t-test & $\mathrm{P}$-values \\
& 6.376 & $\mathrm{P}=0.000^{*}$ \\
\hline \multirow{2}{*}{ 2c vs 2d } & t-test & $\mathrm{P}$-values \\
& 4.914 & $\mathrm{P}=0.004^{*}$ \\
\hline
\end{tabular}

\section{*Significant value $(P<0.05)$}

The mean values of the different subgroups of group 2 are shown in figure 3.

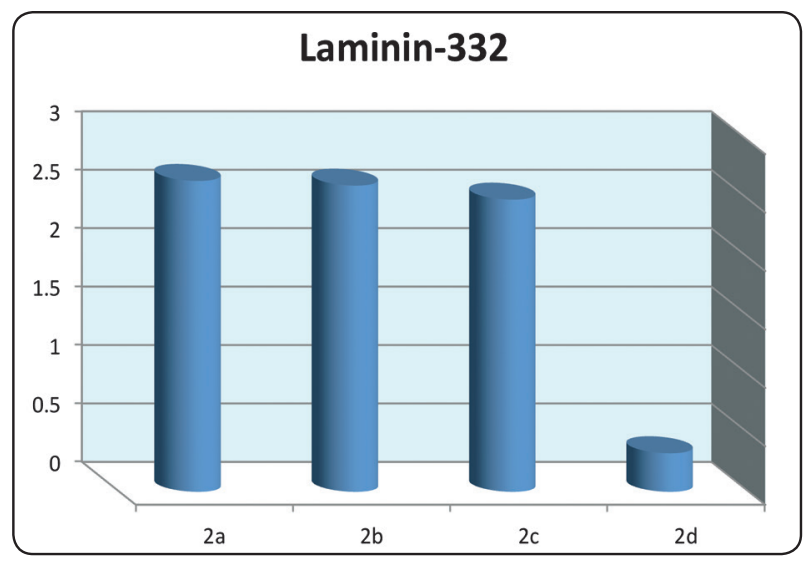

Fig. (3) Mean values of Laminin-332, among the subgroup of ameloblastoma group II (ameloblastoma), 2a (follicular), $2 \mathrm{~b}$ (plexiform), 2c (peripheral ameloblastoma) and 2d (Ameloblastic carcinoma)

TABLE (3) Mean values of Laminin-332, among the subgroup of ameloblastoma:

\begin{tabular}{|c|c|c|c|c|c|}
\hline $\begin{array}{c}\text { Group II } \\
\text { (ameloblastoma) }\end{array}$ & $\begin{array}{c}2 \mathrm{a} \\
\text { (follicular) }\end{array}$ & $\begin{array}{c}2 \mathrm{~b} \\
\text { (plexiform) }\end{array}$ & $\begin{array}{c}2 \mathrm{c} \\
\text { (peripheral }\end{array}$ & $\begin{array}{c}2 \mathrm{~d} \\
\text { (ameloblastic carcinoma) }\end{array}$ & $\begin{array}{c}\text { ANOVA } \\
\text { P-values }\end{array}$ \\
\hline & $2.66 \pm 0.48$ & $2.62 \pm 0.50$ & $2.50 \pm 0.57$ & $0.33 \pm 0.57$ & $\begin{array}{c}18.058 \\
\mathrm{P}<0.001 *\end{array}$ \\
\hline
\end{tabular}

*Significant value $(P<0.05)$ 


\section{DISCUSSION}

The abnormal expression of laminin and its integrin receptors is a hallmark of certain tumor types. They are believed to promote invasion of colon, breast, and skin cancer cells. Along with clinical and pathological information, it has been used to assess tumor invasiveness ${ }^{8}$.

Laminin-332 intense expression in either acanthomatous variant of ameloblastoma and well differentiated squamous cell carcinoma may be due to laminin ability to promote the formation of two separate types of attachment structures, focal adhesions $(\mathrm{SACs})^{4}$.

Also laminin-332 plays an important role in cell migration during tumor invasion and tissue remodeling. Some studies show that laminin-332 and products from its proteolytic degradation are found at the leading front of several tumors and likely induce and/or promote tumor cell migration ${ }^{9}$. This explains decreased expression in poorly differentiated SCC and ameloblastic carcinoma showing aggressive behavior.

The immunoreaction for the laminin-332 gamma2 chain was confined to the tumor cells of the peripheral area of both OSCC cell nests and ameloblast like cells in ameloblastoma. The staining reaction was variable, being mostly weak and fragmented in the basement membrane structures surrounding the neoplastic islands. Some peripheral epithelial cells and some invading small ameloblastoma cell islands showed intense intracellular staining for the gamma 2 chain. These results suggest that laminin-332 may contribute to the histolgical differentiation of both types of tumors ${ }^{10,11}$

Signaling between oral epithelium and mesenchyme always remaining dormant and could be initiated anytime, which is a necessary event during odontogenesis. During this process, the ectomesenchyme has a profound effect on the overlying epithelium and presumably transfers some of its characteristic features or traits to it ${ }^{7}$ this may explain the peripheral expression of laminin332 in oral epithelium ${ }^{12}$.

Progressive loss of expression and continuity of laminnin-332 progressed from dysplasia to more malignant form may be explained by the more aggressive epithelial tumor cells have an increased ability to produce enzymes that degrade basement membrane components, consequently hindering new protein synthesis ${ }^{11}$. These results were linear with ours. Suggesting that there is a correlation between the extent of basement membrane defects and the invasive and metastatic potential of epithelial tumor cells. Also that Laminin-332 deposition outside the basement membrane is an immunohistochemical marker for invasion and is guided by the laminin-332 matrix $^{13}$.

Laminin was seen also around the epidermoid carcinomas but large areas devoid of laminin were constantly seen between the stroma and the neoplastic epithelium. This indicates a lack of proper basement membrane formation by the malignant epidermoid carcinomas. This may be due either to a diminished production or an increased degradation of basement membrane proteins by the carcinoma cells ${ }^{14}$.

It is more possible to study the role of laminin receptor in tumor cell metastases and in the differentiation and function of various normal human epithelial and endothelial cell types through studies done on human mammary carcinomas and colon carcinomas which showed more binding of laminin-332 monoclonal antibody than normal or dysplastic counterparts ${ }^{7}$.

Laminin may be important in mediating interactions of tumor cells with the immune system and have more subtle roles in controlling metastatic behavior $^{15}$

In carcinomas, tumor cells at the invading front strongly express intracellularly the gamma2 chain, 
a component of laminin-332. Explaning the poor expression in some tumor cells in the malignant counterpart. Thus, disregulated cell-laminin interactions are major traits of malignant disorders ${ }^{16}$

Visualization of basement membrane proteins such as laminin can apparently be used in the differential diagnosis between ameloblastomas and their malignant counterparts due to their diminished production or an increased degradation of basement membrane proteins by the carcinomatous cells ${ }^{11,17}$.

\section{CONCLUSION}

Immunohistochemical expression of Laminin-332 is directly proportional to tumor cells differentiation either in ameloblastoma and OSCC

\section{REFERENCES}

1. Ryan MC, Christiano AM, Engvall E et al.: The functions of laminins: lessons from in vivo studies. Matrix Biology; 15(6):369-381, 1996.

2. McGowan KA, Marinkovich and MP: Laminins and human disease. Microsc. Res. Tech.; 51:262-279, 2000.

3. Carter WG, Ryan MC and Gahr PJ: Epiligrin, a new cell adhesion ligand for integrin-3-1 in epithelial basement membranes. Cell 65: 559-610, 1991.

4. Carter WG, Kaur P, Gil SG, Gahr PJ\& Wayner EA: Distinct functions for integrins alpha 3 beta 1 in focal adhesions and alpha 6 beta 4/bullous pemphigoid antigen in a new stable anchoring contact (SAC) of keratinocytes: relation to hemidesmosomes. J. Cell Biol. 111: 3141-3154, 1990.

5. Geuijen CA and Sonnenberg A: Dynamics of the a6ß4 Integrin in keratinocytes. Mol. Biol. Cell 13: 3845-3858, 2002.

6. Nelson K, Helmstaedter V, Moreau C, Lage H.: Estradiol, tamoxifen and ICI182, 780 alter alpha3 and beta1 integrin expression and laminin-1 adhesion in oral squamous cell carcinoma cell cultures. Oral Oncol; 94-9, 2008.

7. Nagamalini B R1, S Suneela, T V Narayan, Balasundari Shreedhar, Leeky Mohanty, Sadhana Shenoy, Uma Swam- inathan: origin of ameloblastoma from basal cells of the oral epithelium- establishing the relation using neuroectodermal marker. Dentistry Section DOI: JCDR, Vol.8p10, 2014 .

8. Tsuruta D, Kobayashi H, Imanishi H.: Laminin-332-integrin interaction: a target for cancer therapy?. Curr. Med. Chem.; 15: 1968-1975, 2008.

9. Horan P.H., Thor A., Schlom J. Rao C.N., and Liotta L.: Expression of Laminin Receptor in Normal and Carcinomatous Human Tissuesas Defined by a Monoclonal Antibody. CANCER RESEARCH 45, 2713-2719, 1985.

10. Shruthy R., Sharada P, Uma Swaminathan, and Nagamalini B.R.: Immunohistochemical expression of basement membrane laminin in histological grades of oral squamous cell carcinoma: A semiquantitative analysis J Oral Maxillofac Pathol. 17(2): 185-189,2013.

11. Yoon HJ1, Jo BC, Shin WJ, Cho YA, Lee JI, Hong SP, Hong SD: Comparative immunohistochemical study of ameloblastoma and ameloblastic carcinoma. Oral Surg Oral Med Oral Pathol Oral Radiol Endod.; 112(6):767-76, 2011.

12. Givant-Horwitz V1, Davidson B, Reich R: Laminin-induced signaling in tumor cells Cancer Lett. 1; 223(1):1-10, 2005 .

13. Henning, K, Berndt A, Katenkamp D.: Loss of laminin-5 in the epithelium-stroma interface: an immunohistochemical maker of malignancy in epithelial lesions of the breast. Histopathology; 34:305-309, 1999.

14. Garcia AS, Hernandez MMA, Sanchez EF : E-caderin, laminin and collagen IV expression in the evolution from dysplasia to oral squamous cell carcinoma. Med Oral Patol Oral Cir Bucal: E100-5, 2005.

15. Lalita Jayaram Thambiah and Satish Kumaran P.: $\beta 1$ integrin and laminin expression in oral squamous cell carcinoma: a comparative study; J Pharm Biomed Sci.; 27(27): 532-536, 2013.

16. Hunt G.: The role of laminin in cancer invasion and metastasis, Exp Cell Biol.; 57(3):165-76. 1989.

17. Patarroyo M1, Tryggvason K, Virtanen I.:.Laminin isoforms in tumor invasion, angiogenesis and metastasis. Cancer Biol. 12(3):197-207, 2002. 